\title{
Emerging use of combination therapies for the management of type 2 diabetes - focus on saxagliptin and dapagliflozin
}

This article was published in the following Dove Press journal: Diabetes, Metabolic Syndrome and Obesity:Targets and Therapy 21 July 2017

Number of times this article has been viewed

\author{
Huan Yu \\ Vincent C Woo \\ Department of Medicine, Division \\ of Endocrinology and Metabolism, \\ Health Sciences Centre, University of \\ Manitoba, Winnipeg, MB, Canada
}

Aims: The aim of this article is to review the safety and efficacy data of dapagliflozin, saxagliptin, and their combination in the management of patients with type 2 diabetes. Evidence for the use of the single-tablet combination formulation is also presented.

Methods: A nonsystematic literature review was performed using the Ovid, PubMed, and Google Scholar databases.

Results: The addition of dapagliflozin/saxagliptin to metformin can lower mean hemoglobin A1c by as much as $1.47 \%$ and lead to weight loss of $0.5-2.0 \mathrm{~kg}$. The risk of genital infections with combination therapy is lower than observed with dapagliflozin alone, suggestive of a protective effect. Adverse event risk at 52-week follow-up was not increased beyond that seen with either monotherapy.

Conclusion: Dapagliflozin/saxagliptin combination is generally well tolerated and is an effective tool in helping patients with diabetes improve glycemic control.

Keywords: SGLT2 inhibitor, DPP4 inhibitor, single-tablet combination, diabetes mellitus

\section{Introduction}

As of 2015, 415 million people around the world have type 2 diabetes (DM2), and this is expected to increase to $>600$ million by $2040 .{ }^{1}$ Tight glycemic control can delay or prevent the development of macrovascular ${ }^{2,3}$ and microvascular complications..$^{4,5}$ As a progressive disease, patients often need multiple antihyperglycemic agents for adequate control. ${ }^{6}$ However, many of the diabetes medications are associated with undesirable side effects. Insulin and secretagogues can increase the risk for hypoglycemia and cause weight gain. ${ }^{7}$ As many as $85 \%$ of patients with DM2 are already overweight, ${ }^{9}$ and weight reduction is a key goal in the management of diabetes as it will reduce insulin resistance and comorbid conditions such as hypertension and dyslipidemia. ${ }^{7}$ Thiazolidinediones can lead to fluid retention as well as weight gain, and may be unsafe for patients with preexisting heart failure. ${ }^{8}$ Metformin use may be limited by gastrointestinal side effects or renal insufficiency. ${ }^{10}$

Given the risks for complications with intensified glycemic control ${ }^{4,11}$ and the different side-effect profiles of various antihyperglycemic agents, an individualized approach must be taken. ${ }^{12,13}$ Although metformin remains first-line in conjunction with lifestyle modification, add-on therapy is left up to patient preference and physician judgment. ${ }^{12,13}$ In their position statement for management of hyperglycemia in DM2, the American Diabetes Association (ADA) and the European Association for the Study of Diabetes (EASD) recommend initiation of combination therapy if hemoglobin A1c (HbAlc)
Department of Medicine, Section of Endocrinology and Metabolism, Health Sciences Centre, University of Manitoba, 838-7I5 McDermot Avenue, Winnipeg, MB, Canada R3E 3P4

$\mathrm{Tel}+\mathrm{I} 2049573218$

Fax +I 2049433516

Email hyu@qmed.ca 
is $\geq 9.0 \%$ to achieve target more quickly. ${ }^{6}$ The Canadian Diabetes Association also recommends initiating combination therapy when HbA1c is $\geq 8.5 \%{ }^{12}$ Similarly, the 2015 American Association of Clinical Endocrinologists/American College of Endocrinology (AACE/ACE) Comprehensive Diabetes Management Algorithm recommends the initiation of combination therapy if $\mathrm{HbA} 1 \mathrm{c}$ is $\geq 7.5 \%$ at diagnosis or if a patient fails to meet glycemic targets after 3 months of monotherapy. ${ }^{14}$ This recognizes the greater difficulty in achieving glycemic control if added therapy is delayed, ${ }^{12}$ as prolonged hyperglycemia can result in glucotoxicity, adding to progressive $\beta$-cell function loss. ${ }^{15}$

Whenever combination therapy is required, drugs using different mechanisms of action are recommended. ${ }^{12}$ The latest guidelines from AACE/ACE and ADA/EASD cite higher level evidence supporting the addition of a dipeptidyl peptidase-4 (DPP4) inhibitor and/or a sodium-glucose cotransporter type 2 (SGLT2) inhibitor. ${ }^{6,14}$ Although SGLT2 inhibitors can increase insulin sensitivity, endogenous glucose production is increased through increased glucagon. ${ }^{16}$ Conversely, DPP4 inhibitors also increase insulin sensitivity but suppresses glucagon, making their pairing mechanistically complementary. ${ }^{17}$ Single-pill combination of dapagliflozin $10 \mathrm{mg}$ /saxagliptin $5 \mathrm{mg}$ has been developed to capitalize on this advantage. ${ }^{18}$ Single-tablet combination (STC) pills have been used in many chronic illnesses such as cardiovascular diseases, AIDS, and diabetes. ${ }^{19}$ By simplifying medication regimen, combination pills have been shown to improve adherence and quality of life..$^{20,21}$

Dapagliflozin/saxagliptin was the first SGLT2 inhibitor and DPP4 inhibitor combination pill approved in Europe. ${ }^{22}$ As of February 2017, this medication has also been approved for use by the U.S. Food and Drug Administration (FDA) as an adjunct to lifestyle modification for the management of DM2. ${ }^{23}$ This article will review the evidence for efficacy and safety of dapagliflozin and saxagliptin as individual and add-on therapy. The five existing phase III studies for their combined use and their role in the management of DM2 are discussed later.

\section{Methods}

A nonsystematic search was performed on Ovid, PubMed, and Google Scholar using a combination of keywords, including SGLT2 inhibitor, DPP4 inhibitor, dapagliflozin, saxagliptin, and diabetes. Relevant articles were selected based on title and abstract review. Ongoing clinical trials were identified from www.clinicaltrials.gov for dapagliflozin and saxagliptin, with a special interest for combined use in diabetes. For completeness, references were also mined from key review articles and meta-analyses.

\section{Saxagliptin}

\section{Mechanism of action}

DPP4 is a class of membrane-bound endopeptidases in a variety of tissues, including the endothelium, liver, and kidneys. ${ }^{24,25}$ They degrade the glucagon-like peptide-1 (GLP-1) and glucose-dependent insulinotropic polypeptide (GIP) secreted in response to oral glucose load. ${ }^{26}$ GIP and GLP-1 augment and sustain insulin release by sensitizing pancreatic $\beta$ cells to glucose concentration. ${ }^{24}$ DPP4 inhibitors increase insulin secretion and GLP-1 levels, thereby suppressing the increased glucagon and hepatic gluconeogenesis that are common in DM2. ${ }^{27,28}$ Thus, although fasting glucose is reduced by saxagliptin, post-prandial hyperglycemia is more potently inhibited, ${ }^{29}$ lowering 24-hour glucose levels by an average of $1 \mathrm{mmol} / \mathrm{L} .{ }^{28}$ Although it inhibits gluconeogenesis, by increasing insulin in a glucose-dependent way, DPP4 inhibitors pose minimal hypoglycemia risk. ${ }^{24,27}$

\section{Pharmacokinetics}

Saxagliptin is a highly potent and selective DPP4 inhibitor, increasing circulating levels of GLP-1 and GIP two- to threefold following a meal. ${ }^{27,30}$ It was approved in 2009 by the FDA for the treatment of DM2 as an adjunct to lifestyle modification, dosed as $2.5 \mathrm{mg}$ or $5 \mathrm{mg}$ once daily. ${ }^{31,32}$ Oral bioavailability is $67 \%$, with peak concentrations within 2 hours and half-life of $2-4$ hours. ${ }^{28,33}$ Saxagliptin is metabolized by the hepatic cytochrome P450 3A4/5 into the major active metabolite BMS-510849, half as potent as the parent drug but with a longer half-life of 3-7.4 hours, ${ }^{33}$ allowing for once-daily dosing. ${ }^{34}$ Parent compound and metabolite are renally cleared. ${ }^{34}$ Therefore, saxagliptin should be reduced to $2.5 \mathrm{mg}$ if creatinine clearance $(\mathrm{CrCl})$ is $\leq 50 \mathrm{~mL} / \mathrm{min}$ or there is concomitant use of strong CYP450 3A4/5 inhibitors (i.e., ketoconazole, ritonavir) to avoid accumulation. ${ }^{32,33}$

\section{Monotherapy}

In clinical studies, saxagliptin monotherapy has been shown to reduce $\mathrm{HbA} 1 \mathrm{c}$ by $0.4 \%-1.1 \%$ after 12 weeks, depending on dose and baseline HbA1c..$^{25,27,35,36}$ Treatment-naïve patients randomized to saxagliptin $2.5 \mathrm{mg}$ and $5 \mathrm{mg}$ achieved placebo-adjusted $\mathrm{HbA} 1 \mathrm{c}$ reductions of $0.45 \%-0.65 \%$ and $0.40 \%-0.73 \%$ as well as placebo-adjusted fasting blood glucose (FBG) reductions of $0.76-1.1 \mathrm{mmol} / \mathrm{L}$ and $0.78-$ $1.3 \mathrm{mmol} / \mathrm{L}$, respectively, after 12-24 weeks depending on the study. ${ }^{31,35,36}$ Post-prandial sugars were also reduced, and greater 
proportions of patients using saxagliptin achieved $\mathrm{HbA} 1 \mathrm{c}$ target of $<7 \%$ compared with placebo..$^{31,35,36}$ Homeostatic model assessment (HOMA) studies confirmed increased $\beta$-cell function. ${ }^{31,36}$ Extended follow-up to 76 weeks still finds sustained placebo-adjusted $\mathrm{HbA} 1 \mathrm{c}$ reductions of $0.12 \%-0.55 \%{ }^{35}$ Weight neutrality and similar hypoglycemia event rates as placebo were demonstrated in studies up to 76 weeks. . $^{31,35,36}$

Jadzinsky et al ${ }^{37}$ compared the efficacy of initiating metformin and saxagliptin $5 \mathrm{mg}$ or $10 \mathrm{mg}$, with either metformin or saxagliptin $10 \mathrm{mg}$ monotherapy in treatment-naïve diabetic patients. By 24 weeks, mean HbA1c dropped by $-2.5 \%$ in metformin/saxagliptin groups compared with $-2.0 \%$ in metformin-only group $(p<0.0001)$ and $-1.7 \%$ in saxagliptinonly group $(p<0.0001) .{ }^{37} \mathrm{FBG}$ and postprandial glucose (PPG) were significantly reduced. ${ }^{37}$ No added benefit was seen with saxagliptin $10 \mathrm{mg} .{ }^{37}$ Of note, reductions in $\mathrm{HbAl}$, FBG, and 2-hour blood glucose level were similar between the metformin- and saxagliptin-monotherapy groups, suggesting comparable efficacy. ${ }^{37}$

\section{Add-on therapy}

Efficacy and safety of saxagliptin as an add-on agent to metformin,${ }^{38-41}$ sulfonylureas, ${ }^{41-43}$ acarbose, ${ }^{41}$ thiazolidinediones, ${ }^{41,44,45}$ and insulin ${ }^{46,47}$ have been established. In general, mean adjusted HbA1c, FBG, and PPG levels were lowered by comparable amounts to saxagliptin monotherapy. Compared against uptitration of metformin (Met-Up), a phase III trial found that saxagliptin $5 \mathrm{mg}$ add-on to submaximal metformin (Saxa-Met) resulted in a similar glycemic control (Met-Up-adjusted mean HbA1c change $-0.38 \pm 0.06 \%$, SaxaMet $-0.47 \pm 0.06 \%$; $p=0.260$ between group difference).$^{40}$ A greater proportion of Saxa-Met than Met-Up reached $\mathrm{HbA} 1 \mathrm{c}$ target of $<7 \%$ (43.8\% vs $35 \%)$ and $<6.5 \%(20.5 \%$ vs $16.8 \%) .{ }^{40}$ Greater adverse events were seen in the Met-Up cohort $(51.0 \%, 75 / 147)$ compared with Saxa-Met $(43.9 \%$, $61 / 139)$, predominantly that of diarrhea. ${ }^{40}$

Compared against uptitration of glyburide, adding saxagliptin to submaximal glyburide resulted in greater $\mathrm{HbA} 1 \mathrm{c}$ reduction at 24 weeks (glyburide-adjusted mean $-0.62 \%$ for saxagliptin $2.5 \mathrm{mg},-0.72 \%$ for $5 \mathrm{mg}$; $p<0.0001 \mathrm{com}$ pared to uptitration). ${ }^{43}$ Mean FBG was also significantly reduced. In all, $22.4 \%$ of the $2.5 \mathrm{mg}$ cohort and $22.8 \%$ of the $5 \mathrm{mg}$ cohort achieved HbAlc $<7 \%$, compared with $9.1 \%$ in uptitrated glyburide $(p<0.0001){ }^{43}$ When followed for 76 weeks, mean HbAlc increased in all groups, consistent with known loss of efficacy of sulfonylureas over time. ${ }^{48}$ However, glyburide-adjusted mean $\mathrm{HbAlc}$ reduction remained statistically significant at $-0.59 \%$
(95\% confidence interval $[\mathrm{CI}]:-0.86,-0.31)$ and $-0.67 \%$ (95\% CI: $-0.94,-0.39$ ), respectively, and a greater proportion of saxagliptin patients maintained $\mathrm{HbAlc}<7 \%$ at 76 weeks. ${ }^{42}$

Active comparator studies have demonstrated saxagliptin to be noninferior to glipizide as an add-on therapy to metformin. ${ }^{49,50}$ At 52 weeks, glipizide-adjusted mean $\mathrm{HbAlc}$ reduction was $-0.06 \%(95 \% \mathrm{CI}:-0.16,0.05),{ }^{49}$ maintained at 104 weeks. ${ }^{50}$ However, saxagliptin group experienced less adverse events (67.1\% saxagliptin vs $72.6 \%$ glipizide), in particular hypoglycemia (3.5\% vs $38.4 \%) .{ }^{50}$ Glipizideadjusted mean weight change was also significant at $-2.8 \mathrm{~kg}$ (95\% CI: $-3.32,-2.20) .^{50}$

Saxagliptin add-on to insulin has also been studied. ${ }^{46,47}$ Barnett et a ${ }^{46}$ randomized 455 patients inadequately controlled on stable-dose insulin (total daily dose [TDD] 30-150 U/day) with or without metformin to saxagliptin $5 \mathrm{mg}$ versus placebo. Fasting serum glucose did not differ, but postprandial area under curve was reduced with saxagliptin at 24 weeks $(p=0.0011) .{ }^{46}$ $\mathrm{HbA} 1 \mathrm{c}$ reduction was evident by 12 weeks and sustained at 24 weeks, with placebo-adjusted change of $-0.41 \%$ ( $95 \%$ CI: $-0.59,-0.24 ; p<0.0001)$ with saxagliptin, regardless of baseline metformin use. ${ }^{46}$ Weight and risk of hypoglycemia did not differ between groups; however, difference in TDD was only $3.3 \mathrm{U}$ by the end of trial with $17.3 \%$ of saxagliptin cohort achieving target $\mathrm{HbA} 1 \mathrm{c}<7 \%$ compared with only $6.7 \%$ on placebo ${ }^{46}$ suggestive of under titration, which may have attenuated the differences in complication.

\section{Tolerability and safety}

Saxagliptin is generally well tolerated, with a low risk of hypoglycemia given its glucose-dependent effects. ${ }^{51-53}$ In monotherapy and as an add-on agent, adverse event, discontinuation, and hypoglycemia rates were typically low and balanced, without added weight gain. ${ }^{31,35,36,40,44}$ When added to submaximal-dose metformin, saxagliptin produced comparable glycemic control without the increased gastrointestinal side effects with uptitrated metformin. ${ }^{40}$ Compared to glipizide add-on to metformin, saxagliptin had similar efficacy, but with significantly less hypoglycemia and weight gain. ${ }^{50}$ When added to submaximal glyburide, glycemic control significantly improved, with a minimal increase in confirmed hypoglycemia (5.2\% with saxagliptin $2.5 \mathrm{mg}$, $3.2 \%$ with saxagliptin $5 \mathrm{mg}$, and $3.4 \%$ with uptitration), and most were only mild or moderate in intensity. ${ }^{42}$

Hirshberg et al ${ }^{51}$ performed a meta-analysis of 20 placebo and active comparator phase IIb/III trials to examine the safety of saxagliptin. Pooled analysis of 9,156 patients found that saxagliptin and controls had similar incidence rate ratios 
(IRRs) of death (2.5 mg dose IRR=0.46, 95\% CI: $0.10,-1.82$; $5 \mathrm{mg}$ dose IRR $=0.73$, 95\% CI: $0.31,-1.68)$, serious adverse events $(2.5 \mathrm{mg}$ dose IRR $=0.96,95 \% \mathrm{CI}: 0.7,-1.33 ; 5 \mathrm{mg}$ dose IRR $=1.03$, 95\% CI: $0.84,-1.26)$, and discontinuation due to adverse events $(2.5 \mathrm{mg}$ dose $\mathrm{IRR}=1.14,95 \% \mathrm{CI}: 0.74$, $-1.78 ; 5 \mathrm{mg}$ dose IRR=1.10, 95\% CI: 0.84, -1.43). ${ }^{51}$ When use of confounding medication (i.e., insulin, sulfonylurea) was excluded, saxagliptin was not associated with increased reported or confirmed hypoglycemia. ${ }^{51}$ No increased risk for pancreatitis was seen. ${ }^{51}$ Overall, saxagliptin was felt to have a good safety profile.

SAVOR-TIMI randomized 16,492 patients with increased cardiovascular risk to saxagliptin or placebo. ${ }^{54}$ After median follow-up of 2.1 years, the primary composite end point of cardiovascular death, nonfatal myocardial infarction, and nonfatal ischemic stroke occurred in 3.7/100 person-years on saxagliptin and placebo, yielding an HR of 1.00 (95\% CI: $0.89,-1.12) .{ }^{54}$ However, more patients on saxagliptin was hospitalized for heart failure $(\mathrm{HR}=1.27$; 95\% CI: 1.07 , $-1.51 ; p=0.007) .{ }^{54}$ Reexamination of data found this risk increased within the first 12 months of therapy $(\mathrm{HR}=1.52$; 95\% CI: $1.17,-1.96 ; p=0.0015)$, after which there was no difference $(\mathrm{HR}=1.05 ; 95 \% \mathrm{CI}: 0.81,-1.35 ; p=0.73) .{ }^{55}$ Several clinical risk factors identified patients at a high absolute risk for heart failure, particularly prior history of heart failure $\left(\chi^{2}=231.99\right.$, adjusted $\mathrm{HR}=4.18 ; 95 \% \mathrm{CI}: 3.48$, $-5.02 ; p<0.01)$, estimated glomerular filtration rate (eGFR) $\leq 60 \mathrm{~mL} / \mathrm{min}\left(\chi^{2}=49.86\right.$, adjusted $\mathrm{HR}=2.00 ; 95 \% \mathrm{CI}: 1.65$, $-2.42 ; p<0.01)$, urine albumin-creatinine $\geq 3.4 \mathrm{mg} / \mathrm{mmol}$ $\left(\chi^{2}=35.77\right.$, adjusted $\left.\mathrm{HR}=1.89 ; 95 \% \mathrm{CI}: 1.54,-2.34, p<0.01\right)$, and elevated baseline $\mathrm{N}$-terminal pro b-type natriuretic peptide (NT-proBNP) levels (stepwise increase with each quartile). ${ }^{55}$ As yet, there is no identified pathophysiology for the increased risk of hospitalization for heart failure $(0.7 \%$ absolute risk over 2 years). ${ }^{53,55}$ No association with volume overload (as evidenced by increased NT-proBNP, weight, or peripheral edema) or myocardial toxicity (via increased hsTNT or hsCRP) was seen in SAVOR-TIMI, ${ }^{45}$ suggesting saxagliptin safety in cardiovascular patients outside of the aforementionned risk factors.

No renal risks were detected in SAVOR-TIMI, and at the end of trial, more patients in the saxagliptin group showed either lack of progression or even improvement in microalbuminuria; ${ }^{54}$ the implications for this on long-term cardiovascular outcomes are unknown. ${ }^{53-55}$ There was no increased risk for pancreatitis, ${ }^{54}$ as supported by other systematic reviews and meta-analyses. ${ }^{51,56}$ Although the risk of pancreatic cancer is difficult to assess given the long follow- up required, a meta-analysis of randomized controlled trials that included DPP4 inhibitors, totaling 68,318 patients with 52,464 patient-years, suggested no increased risk compared with placebo or other antihyperglycemic agents (odds ratio $[\mathrm{OR}]=0.72,95 \% \mathrm{CI}: 0.32,-1.61 ; p=0.42) .{ }^{56}$

Safety in patients aged $\geq 65$ years was assessed in a pooled analysis of five phase III trials, totaling 428 individuals. ${ }^{57}$ Incidence of adverse events, including hypoglycemia, was similar between treatment and placebo, and unchanged compared to younger subgroups. ${ }^{57}$ Investigators of SAVOR-TIMI also performed subgroup analysis in elderly ( $\geq 65$ years) and very elderly ( $\geq 75$ years) patients, with no difference in primary cardiovascular outcomes between saxagliptin and placebo (elderly $\mathrm{HR}=0.92 ; 95 \% \mathrm{CI}$ : $0.79,-1.06$; very elderly $\mathrm{HR}=0.95 ; 95 \% \mathrm{CI}: 0.75,-1.22) .{ }^{58}$ Proportion of hypoglycemia was minimally higher in the saxagliptin group ( $<65$ years, $14.5 \%$ vs $12.4 \%$ placebo, $p=0.006$; $\geq 65$ years, $16.0 \%$ vs $14.4 \%$ placebo, $p=0.043$ ), but this was related to background sulfonylurea use and baseline $\mathrm{HbA} 1 \mathrm{c}<7 \%{ }^{58}$

\section{Dapagliflozin}

\section{Mechanism of action}

SGLTs are adenosine triphosphate-dependent, transmembrane glucose transporters. SGLT2s are almost exclusively found in the S1 segment of the proximal renal tubules..$^{59,60}$ In rodent studies and in healthy individuals, they have been shown to reabsorb $\sim 90 \%$ of the average $180 \mathrm{~g}$ filtered glucose, with the SGLT1s in the distal proximal tubules reabsorbing the remainder. ${ }^{60,61}$ As plasma glucose increases, reabsorption increases linearly and then plateaus as SGLTs become saturated. Patients with DM2 have increased number of SGLT2s, but whether this is related to pathogenesis or as a consequence of DM2 is unclear. ${ }^{62}$ Dapagliflozin is a highly selective and potent reversible inhibitor of SGLT2. ${ }^{63} \mathrm{By}$ inhibiting the reabsorption of up to $50 \%$ of filtered glucose, it induces glycosuria of $\sim 70 \mathrm{~g} /$ day, reducing fasting serum glucose by $\sim 1 \mathrm{mmol} / \mathrm{L}$ compared with placebo. ${ }^{15}$ Greater reductions in PPG than fasting glucose are observed, suggesting renal excretion as one of the physiologic mechanisms in maintaining euglycemia after eating. ${ }^{15,64}$ In patients with baseline glycosuria due to poorly-controlled diabetes, the glucose-lowering effects of this medication are not attenuated; mean HbA1c and fasting glucose reductions with dapagliflozin were much higher in those with baseline HbA1c $\geq 10.1 \%{ }^{65}$ Hyperinsulinemic euglycemia clamp studies suggest that dapagliflozin improves insulin resistance, ${ }^{61}$ whereas HOMA- $\beta$ assessments in phase III trials 
demonstrate improved $\beta$-cell function, purportedly through decreased weight and glucotoxicity. ${ }^{66}$

\section{Pharmacokinetics}

Dapagliflozin is rapidly absorbed with $78 \%$ oral bioavailability, ${ }^{67}$ reaches peak plasma levels by 2 hours, ${ }^{64}$ and has a half-life of 12.9 hours. ${ }^{68}$ In ascending dose studies, nearmaximal rates of glycosuria are induced with dapagliflozin $20 \mathrm{mg}$ daily or higher, with sustained $3 \mathrm{~g} / \mathrm{h}$ excretion for at least 24 hours in healthy and diabetic subjects. ${ }^{64}$ Its metabolism is catalyzed by multiple CYP enzymes, placing it at a low risk for drug interactions. ${ }^{64}$ The drug is mainly inactivated by the hepatic UGT1A9 enzyme; ${ }^{67}$ although the metabolite BMS-511926 is active, it is not produced unless dapagliflozin $\geq 50 \mathrm{mg}$ is used. ${ }^{64}$ Half-life of the parent drug is 16 hours, with $<2.5 \%$ of the drug excreted in the urine. ${ }^{64}$ Dapagliflozin was approved by the FDA in 2014 for the treatment of DM2 inadequately controlled by lifestyle modification. ${ }^{67}$ Usual dose is $5 \mathrm{mg}$ or $10 \mathrm{mg}$ daily, as higher doses have been associated with tolerability and safety issues. ${ }^{69}$ Use is contraindicated in the setting of moderate renal impairment $\left(\mathrm{CrCl}<60 \mathrm{~mL} / \mathrm{min} / 1.73 \mathrm{~m}^{2}\right){ }^{70}$

\section{Clinical efficacy (dapagliflozin) Monotherapy}

In phase III clinical trials of treatment-naïve DM2 patients, dapagliflozin $5 \mathrm{mg}$ and $10 \mathrm{mg}$ produced mean placebo-adjusted $\mathrm{HbA} 1 \mathrm{c}$ reductions of approximately $-0.54 \%$ and $-0.66 \%$, respectively, in studies up to 24 weeks. $^{15,65}$ When followed to 102 weeks, Bailey et $\mathrm{al}^{71}$ found sustained placebo-adjusted $\mathrm{HbA} 1 \mathrm{c}$ reductions of $-0.69 \%$ (95\% CI: $-1.37,0.02 ; p=0.44)$ and $-1.12 \%$ (95\% CI: $-1.79,-0.44 ; p=0.001)$, respectively, even though metformin $500 \mathrm{mg}$ daily was added to placebo at week 25 for ethical reasons. Mean fasting serum glucose reductions were seen as early as 1 week, achieving $-1 \mathrm{mmol} / \mathrm{L}$ beyond placebo effects. ${ }^{15,65,71}$ Furthermore, dapagliflozin efficacy was similar to metformin monotherapy for $\mathrm{HbA} 1 \mathrm{c}$ and FBG reduction at 12 weeks. ${ }^{15}$ Although at 24 weeks dapagliflozin $5 \mathrm{mg}$ and $10 \mathrm{mg}$ resulted in mean baseline weight reductions of $-2.8 \mathrm{~kg}$ and $-3.2 \mathrm{~kg}$, respectively, compared with $-2.2 \mathrm{~kg}$ in placebo group, ${ }^{65}$ followup to 102 weeks showed that only dapagliflozin $10 \mathrm{mg}$ produced sustained and significant placebo-adjusted mean weight loss of $-2.60 \mathrm{~kg}(95 \% \mathrm{CI}:-4.70,-0.49 ; p=0.016){ }^{71}$ Despite its mild diuretic effect, clinical trials using dualenergy X-ray absorptiometry demonstrated that weight loss with dapagliflozin is attributable to fat reduction. ${ }^{72,73}$

\section{Add-on therapy}

Dapagliflozin is also effective at further lowering HbA1c when added to other antihyperglycemics including secretagogues, ${ }^{74,75}$ metformin, ${ }^{76-78}$ pioglitazone, ${ }^{79}$ DPP4 inhibitors, ${ }^{80,81} \alpha$-glucosidase inhibitors, ${ }^{76}$ and insulin. ${ }^{82-84}$ When added to metformin, glimepiride, metformin/sitagliptin, or pioglitazone, dapagliflozin $5 \mathrm{mg}$ and $10 \mathrm{mg}$ produced placebo-adjusted mean $\mathrm{HbA} 1 \mathrm{c}$ reductions of $0.40 \%-0.49 \%$ and $0.54 \%-0.68 \%$ at 24 weeks, respectively, ${ }^{75,76,79,80}$ with sustained if not greater reductions at 48 weeks. ${ }^{74,79}$ Mean FBG decreased by $0.86-1 \mathrm{mmol} / \mathrm{L}$ beyond placebo. ${ }^{75,76,79} \mathrm{~A}$ further $11 \%-17 \%$ and $15 \%-18 \%$ of patients on dapagliflozin $5 \mathrm{mg}$ and $10 \mathrm{mg}$ achieved $\mathrm{HbA} 1 \mathrm{c}$ targets of $<7 \%$ than placebo at 24 weeks, ${ }^{75,76}$ maintained at 48 weeks. ${ }^{74}$ Despite the weightpromoting effects of sulfonylureas, add-on dapagliflozin allowed for mean weight reductions from baseline; the $5 \mathrm{mg}$ and $10 \mathrm{mg}$ doses resulted in placebo-adjusted mean weight loss of $-0.77 \mathrm{~kg}$ and $-1.64 \mathrm{~kg}$, respectively. ${ }^{74}$ With pioglitazone, although mean weight was mildly increased from baseline, add-on dapagliflozin had a sustained weight-sparing effect, with placebo-adjusted weight changes of $-1.64 \mathrm{~kg}$ and $-2.3 \mathrm{~kg}$ at 48 weeks, depending on dose $;^{79}$ less peripheral edema was reported in treatment groups $(4.3 \%$ for $5 \mathrm{mg}$ and $2.1 \%$ for $10 \mathrm{mg}$ ) compared with placebo $(6.5 \%){ }^{79}$

Wilding et $\mathrm{al}^{82}$ randomized 808 patients on moderate insulin therapy (mean TDD=73.7-79.6 U) and up to two oral antihyperglycemic agents to dapagliflozin add-on or placebo. Despite longstanding disease (mean 13.6 years), HbA1c reduction was evident as early as 4 weeks, and by 24 weeks, placebo-adjusted mean $\mathrm{HbA} 1 \mathrm{c}$ reductions in dapagliflozin $5 \mathrm{mg}$ and $10 \mathrm{mg}$ were $-0.49 \%$ (95\% CI: $-0.65,-0.34$; $p<0.001)$ and $-0.57 \%$ (95\% CI: $-0.72,-0.42 ; p<0.001)$, respectively, and maintained at 48 weeks. ${ }^{82}$ Subanalysis found that patients on insulin and oral agents at baseline attained a numerically greater placebo-adjusted $\mathrm{HbA} 1 \mathrm{c}$ reduction (48 weeks, dapagliflozin $5 \mathrm{mg}-0.58 \%$ [95\% CI: -0.79 , -0.37 ], dapagliflozin $10 \mathrm{mg}-0.61 \%$ [95\% CI: $-0.82,-0.40])$ than those on baseline insulin alone (48 weeks, dapagliflozin $5 \mathrm{mg}-0.39 \%$ [95\% CI: $0.63,-0.15]$, dapagliflozin $10 \mathrm{mg}$ $-0.46 \%$ [95\% CI: $-0.71,-0.21]){ }^{82}$ Extended follow-up to 104 weeks found that placebo-adjusted $\mathrm{HbAlc}$ reduction maintained significance at $-0.40 \%$ with dapagliflozin $(95 \%$ $\mathrm{CI}:-0.6,-0.2 ; p<0.001) .{ }^{84}$ Insulin requirements decreased steadily with both dapagliflozin doses, with placebo-adjusted TDD change of $-19.2 \mathrm{U}(95 \% \mathrm{CI}:-25.5,-12.9 ; p<0.0001)$ for dapagliflozin $10 \mathrm{mg}$ at 104 weeks. ${ }^{84}$ Weight loss was evident as early as 1 week, with placebo-adjusted mean change of $-1.82 \mathrm{~kg}(95 \% \mathrm{CI}:-2.56,-1.07 ; p<0.001)$ and 
$-2.43 \mathrm{~kg}$ (95\% CI: $-3.18,-1.68 ; p<0.001)$, respectively, at 48 weeks. ${ }^{82}$ By 104 weeks, placebo-adjusted weight reduction was maintained, with mean $-3.33 \mathrm{~kg}(95 \% \mathrm{CI}:-4.38,-2.27$; $p<0.0001)$ in the $10 \mathrm{mg}$ cohort. $^{84}$

Long-term efficacy was established by Del Prato et $\mathrm{al}^{77}$ comparing dapagliflozin with glipizide add-on to metformin over 4 years, as an extension of the 104-week study by Nauck et al. ${ }^{78}$ Although the mean $\mathrm{HbAlc}$ change from baseline of $-0.52 \%$ at 52 weeks ${ }^{78}$ was gradually attenuated by 4 years $(-0.10 \%$ [95\% CI: $-0.25,0.05]),{ }^{77}$ the glipizide-adjusted difference was sustained ( 2 years: $-0.18 \%[95 \% \mathrm{CI}:-0.33,-0.03]]^{78}$ 4 years: $-0.30 \%[95 \% \mathrm{CI}:-0.51,-0.09]) \cdot{ }^{77}$ Mean weight loss in the dapagliflozin group at 104 weeks was $-3.7 \mathrm{~kg}(95 \%$ CI: $-4.2,-3.2)$, producing a glipizide-adjusted difference of $-5.1 \mathrm{~kg}(95 \% \mathrm{CI}:-5.7,-4.4)^{78}$ sustained at 4 years. ${ }^{77}$

\section{Safety/tolerability}

Across various phase III trials, dapagliflozin was generally well tolerated with similar rates of adverse events as comparator and unlikely to lead to discontinuation. ${ }^{68}$ Adverse events of special interest include hypoglycemia, hypotension, renal dysfunction, and genitourinary tract infections as related to the mechanism of action of dapagliflozin.

Hypoglycemia frequency with dapagliflozin is low and comparable to other therapies, typically $<4 \%$, and unlikely to be severe. ${ }^{76,79,80,85}$ Notable exceptions are when this medication is added to sulfonylureas or insulin, due to the intrinsic propensity of these medications for hypoglycemia. ${ }^{85}$ When added to glimepiride, Strojek et al ${ }^{74}$ found that a higher proportion of dapagliflozin-treated patients experienced hypoglycemia at 48 weeks ( $5 \mathrm{mg}$ dose $10.3 \%, 15 / 145 ; 10 \mathrm{mg}$ dose $11.3 \%, 17 / 151)$ than placebo $(6.8 \%, 10 / 146)$. In their proof-of-concept study of dapagliflozin add-on to insulin, Wilding et $\mathrm{a}^{83}$ found an increased prevalence of hypoglycemia (10 mg 29.2\%, 7/24) compared with placebo $(13.0 \%$, $3 / 23)$ at 12 weeks, despite both cohorts having prophylactically reduced their TDD by $50 \%$. In their subsequent study of 808 patients on insulin followed to 104 years however, incidence of hypoglycemia was not increased with dapagliflozininsulin $(60.7 \%, 119 / 196)$ compared with placebo-insulin (61.9\%, 122/197), and most were not severe. ${ }^{84}$ Compared with glipizide add-on to metformin, dapagliflozin add-on had consistently lower hypoglycemia rates over 4 years $(5.4 \%$ [22/406] compared to $51.5 \%$ [210/408]). ${ }^{77}$

Owing to the mild diuretic effect of dapagliflozin, concerns have been raised about the potential for hypotension, hypovolemia, and renal impairment. In monotherapy and combination therapy trials, dapagliflozin lowered systolic blood pressure by a mean of $2.4-7.5 \mathrm{mmHg}^{15,77,78,84}$ and diastolic blood pressure by $2.9-4.0 \mathrm{mmHg}{ }^{84}$ However, these were not associated with rebound tachycardia, ${ }^{15,84}$ decreased eGFR, ${ }^{77,78,84}$ or increased hypotensive/hypovolemic event rates, ${ }^{77,78,80,84}$ even after 4 years. ${ }^{77}$ Pooled analysis of 12 placebo-controlled trials found volume-related events to be low (dapagliflozin $0.8 \%$ [27/3, 291], placebo $0.4 \%$ $[5 / 1,393]))^{85}$ risks were higher in patients concomitantly treated with loop diuretics (6.1\% versus $1.8 \%){ }^{85}$ Majority of reported renal events are laboratory based, and pooled analysis of studies up to 102 weeks showed a $2.0 \%$ event rate with dapagliflozin compared with $1.6 \%$ with placebo. ${ }^{85}$ There is often a mild, transient, and reversible decrease in eGFR in the first few weeks after initiation, consistent with a mild osmotic diuresis. ${ }^{80,85}$ Some evidence suggests that dapagliflozin may be renoprotective. Heerspink et a ${ }^{86}$ performed a post hoc analysis of phase III clinical trials involving patients with poorly controlled diabetes and hypertension with nephropathy despite angiotensin-converting enzyme inhibitor (ACEi)/angiotensin receptor blocker (ARB). A total of 356 patients were identified with mean baseline eGFR $84 \mathrm{~mL} /$ $\mathrm{min} / 1.73 \mathrm{~m}^{2}$ and $\mathrm{uACR}$ of $\sim 76.5 \mathrm{mg} / \mathrm{g} .{ }^{86}$ After 12 weeks of randomization to dapagliflozin $10 \mathrm{mg}$, the treatment group saw a placebo-adjusted decrease in albuminuria of $-33.2 \%(95 \%$ CI: $-45.4,-18.2)^{86}$ comparable to other SGLT2 inhibitors. ${ }^{87}$ In all, $40.5 \%$ of the dapagliflozin cohort improved from microor macroalbuminuria to a lower category compared with only $23.9 \%$ placebo ${ }^{86}$ Multiple regression analysis showed that mean change in $\mathrm{HbA1}$, systolic blood pressure, body weight, and eGFR was low $\left(r^{2}=11.5 \%, p<0.0001\right)$, suggesting that the albuminuria change is independent of these. ${ }^{86}$ SGLT2 inhibitors reduce intraglomerular pressure by a different mechanism as ACEi/ARB, and as this has been associated with long-term renal preservation, the authors proposed that dapagliflozin may have this long-term benefit. ${ }^{86}$ NCT02547935 is an upcoming trial of dapagliflozin in patients with chronic kidney disease and will help answer this hypothesis.

Although diabetes itself is associated with increased genital infections, ${ }^{88}$ incidence is increased with dapagliflozin use. ${ }^{68}$ Pooled analysis of 12 placebo-controlled studies found that $5.1 \%(167 / 3,291)$ of patients on dapagliflozin $2.5-10 \mathrm{mg}$ experienced genital infections compared with only $0.9 \%$ on placebo $(12 / 1,393)$, without dose-dependent effect. ${ }^{85,88}$ Most common events were vulvovaginal mycotic infections, and risk was increased in both males and females. ${ }^{88}$ However, overall risk increase was highest in females and those with a history of recurrent vulvovaginal infections; ${ }^{88}$ small increases were also noted for patients aged $<65$ years 
and with body mass index (BMI) $\geq 30 .^{88}$ Time to first event was typically within the first 24 weeks. ${ }^{84,85,88}$ Infections were usually mild or moderate, responded to standard therapy, and rarely required discontinuation of therapy. ${ }^{77,84,85} \mathrm{In}$ their pooled analysis, Ptaszynska et a ${ }^{85}$ found that only $4.3 \%$ of events in dapagliflozin-treated patients required repeat treatment; recurrence rates were low for both placebo $(8.3 \%)$ and treatment (17.4\%) arms. ${ }^{85}$

A smaller, increased incidence for urinary tract infections (UTIs) is also seen with dapagliflozin. Pooled analysis found reported symptoms suggestive of UTIs in $4.8 \%$ of dapagliflozin-treated patients $(158 / 3,291)$ compared with $3.7 \%$ of placebo-treated patients $(52 / 1,393)$, without dosedependent relationship. ${ }^{85}$ Where cultures were performed, typical pathogens were identified. ${ }^{85,89}$ Subgroup analysis showed more events occurred in women ${ }^{85,89}$ and patients aged $\geq 65$ years..$^{89}$ Although a history of recurrent UTIs increased incidence (17.1-21.1\%) compared to those without (3.2$5.5 \%$ ), use of dapagliflozin did not increase the risk further. ${ }^{89}$ Events were typically mild or moderate, occurring within the first 24 weeks, and required only one course of antibiotics without the need for dapagliflozin discontinuation. ${ }^{77,84,85,89}$ Pyelonephritis was a rare complication, and in their 14-study pooled analysis up to 102 weeks, Ptaszynska et al ${ }^{85}$ found only three cases $(0.1 \%)$ with dapagliflozin compared with three cases $(0.2 \%)$ with placebo.

Pooled analysis of short-term studies found a small mean percentage increase in fasting low-density lipoprotein (LDL) with dapagliflozin $(0.6 \%-2.7 \%)$ versus placebo $(-1.9 \%)$ and an increase in high-density lipoprotein (HDL; $3.8 \%-6.5 \%$ vs $3.8 \%$, respectively). ${ }^{85}$ This was also observed by Wilding et a ${ }^{84}$ in their 104-week study, with increased mean HDL (dapagliflozin 5/10 mg 13.8\% [95\% CI: 7.1, 20.8] and $10 \mathrm{mg} 7.3 \%$ [95\% CI: 4.2, 10.4], placebo $5.1 \%$ [95\% CI: $-0.8,11.3]$ ) and a small increase in LDL (dapagliflozin 5/10 mg 5.0\% [95\% CI: $-1.8,12.2]$ and $10 \mathrm{mg}$ $1.7 \%$ [95\% CI: $-4.0,7.7]$, placebo $-3.4 \%$ [95\% CI: -9.1 , 2.7]) from baseline. The mechanism for this drug effect has not been fully elucidated. In diet-induced hyperlipidemic hamsters, treatment with SGLT2 inhibitor empagliflozin resulted in a $25 \%$ increase in LDL during fasting states only. ${ }^{90}$ This was associated with a $116 \%$ increase in ketone bodies and a $49 \%$ increase in free fatty acids, ${ }^{90}$ demonstrating the increased lipid catabolism seen in human beings with prolonged SGLT2 inhibitor use. ${ }^{91}$ This shift from glucose to fat oxidation has also been demonstrated in patients on dapagliflozin after only 2 weeks, ${ }^{92}$ and this likely accounts for the small changes seen in lipid levels.
However, no signal of increased cardiovascular risk has been associated with these changes. A meta-analysis of 21 phase IIb/III clinical trials examining cardiovascular outcomes in 5,936 patients exposed to dapagliflozin $(6,668$ patient-years) and 3,403 controls (3,882 patient-years) found no increased risk for major adverse cardiovascular event (MACE) outcomes (HR=0.772; 95\% CI: $0.543,1.097$ ) or MACE with unstable angina (HR $=0.787 ; 95 \% \mathrm{CI}: 0.579$, 1.070). ${ }^{93}$ Risk ratio remained equivocal in subgroup analyses with high-risk patients aged $\geq 65$ years. ${ }^{93}$ There was a signal for protective effect against hospitalization for heart failure in the treatment group ( $\mathrm{HR}=0.361 ; 95 \% \mathrm{CI}: 0.156,0.838) .{ }^{93} \mathrm{In}$ a separate systematic review and meta-analysis, SGLT2 inhibitor use was protective for MACE (relative risk $[\mathrm{RR}]=0.84$; 95\% CI: $0.75,0.95 ; P^{2}=43 \%$ ) and MACE-plus (RR=0.85; 95\% CI: $0.77-0.95 ; I^{2}=24 \%$ ), largely driven by the results of EMPA-REG. ${ }^{94}$ However, dapagliflozin-specific data also showed benefit for MACE (RR=0.67; 95\% CI: 0.48, 0.94) and MACE-plus (RR=0.69; 95\% CI: 0.51, 0.92).$^{94}$ Mechanism for these cardioprotective effects appears disproportionate to the glycemic benefits and is likely multifactorial. ${ }^{94}$ Some authors attribute it to the lowering of blood pressure, ${ }^{77,95}$ weight loss, ${ }^{77}$ and mild diuretic ${ }^{95}$ benefits; others note that these effects are small, ${ }^{94,95}$ and the nonsignificant increase to stroke seems inconsistent with blood pressure control as a primary mechanism. ${ }^{94}$ Recently, a small, open-label, prospective study of DM2 patients on oral antihyperglycemic agents found that the addition of dapagliflozin specifically increased the large buoyant fraction of LDL cholesterol, with a decrease in the proportion of small dense LDL; ${ }^{96}$ the latter is more atherogenic and strongly associated with coronary artery disease. ${ }^{96}$ Therefore, although dapagliflozin has been associated with minor increases to LDL by inducing a shift from glucose to lipid catabolism, there is no associated increase in cardiovascular risk; in fact, evidence suggests dapagliflozin may be protective, possibly related to the composition. DECLARE-TIMI 58 (NCT01730534) - a large, prospective, randomized, and placebo-controlled study on cardiovascular outcomes with dapagliflozin - followed for up to 6 years - will better clarify this issue.

In 2016, the FDA strengthened its label warning for SGLT2 inhibitor use and the development of diabetic ketoacidosis (DKA), in response to 73 reported cases between 2013 and $2015 .{ }^{97}$ This concern prompted a position statement by the AACE. ${ }^{98}$ It highlighted a preexisting ketoacidosis event rate of $0.32-2.0 / 1,000$ patient-years in DM2 patients compared with $0.2-0.8 / 1,000$ patient-years in large clinical trials with SGLT2 inhibitors, suggesting that incidence may 
not actually be increased with SGLT2 inhibitor use. Safety analyses from pooled dapagliflozin clinical trials did not identify any increased risk for DKA, ${ }^{68,85}$ and 2- and 4-year follow-up studies did not identify any events. ${ }^{77,84}$ AACE committee reviewed the DKA cases, and most occurred in patients with insulin deficiency, including long-standing DM2. ${ }^{98}$ Cases were often associated with very low carbohydrate diets or times of stress (i.e. surgery) when lipolysis and counterregulatory hormones are increased.${ }^{98}$ Owing to their mechanism of action, SGLT2 inhibitors can induce DKA with lower-than-expected glucose levels, and clinical suspicion must remain high in patients with classical symptoms even without hyperglycemia. ${ }^{98}$ DKA risk should be minimized by holding SGLT2 inhibitors at least 24 hours before predictable stress and during acute illness, avoiding very low carbohydrate diets or excessive alcohol, and avoiding routine or excessive insulin reduction with drug initiation in patients with insulin-dependent DM2.$^{98}$ However, the risk-benefit ratio still greatly support the use of this medication in DM2.

\section{Dapagliflozin/saxagliptin combination}

The combination pill comprising dapagliflozin/saxagliptin $10 \mathrm{mg} / 5 \mathrm{mg}$ once daily is approved for management of type 2 diabetes in the United States and Europe. In the United States, this drug can be initiated for patients with inadequate glycemic control despite dapagliflozin $10 \mathrm{mg}$, or are already on free combination of the two medications, ${ }^{23}$ whereas in Europe, it is only approved for patients with inadequate control on metformin, a sulfonylurea and a monocomponent of the pill. ${ }^{18}$ Use is contraindicated in patients with moderate-severe renal impairment, defined as eGFR $<45 \mathrm{~mL} / \mathrm{min} / 1.73 \mathrm{~m}^{2}$ by the FDA. ${ }^{23}$

\section{Efficacy}

In total, five completed phase III trials have examined the efficacy and safety of combined dapagliflozin and saxagliptin use in diabetes management; key demographic and baseline characteristics are summarized in Table 1 . The key primary and secondary end points are summarized in Table 2, with relevant safety results summarized in Table $3 \mathrm{~A}$ and $\mathrm{B}$.

In the first of these trials, Rosenstock et a ${ }^{99}$ randomized 534 patients with diabetes poorly controlled with metformin monotherapy, to dapagliflozin/saxagliptin add-on versus saxagliptin $5 \mathrm{mg}$ or dapagliflozin $10 \mathrm{mg}$ single add-on. Baseline median $\mathrm{HbA} 1 \mathrm{c}$ was $8.9 \%$ with a mean duration of disease of 7.6 years. ${ }^{99}$ After 24 weeks, mean adjusted HbA1c change with combined add-on was $-1.47 \%$ (95\% CI: $-1.62,-1.31)$, significantly greater than with saxagliptin $(-0.88 \% ; 95 \% \mathrm{CI}$ :

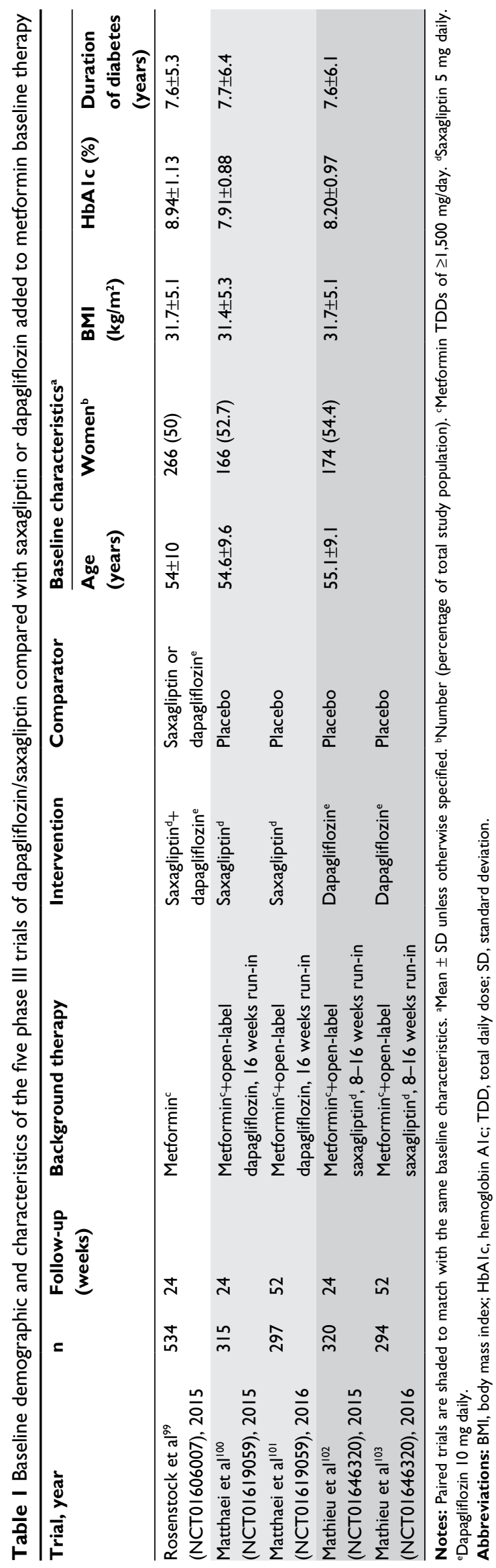




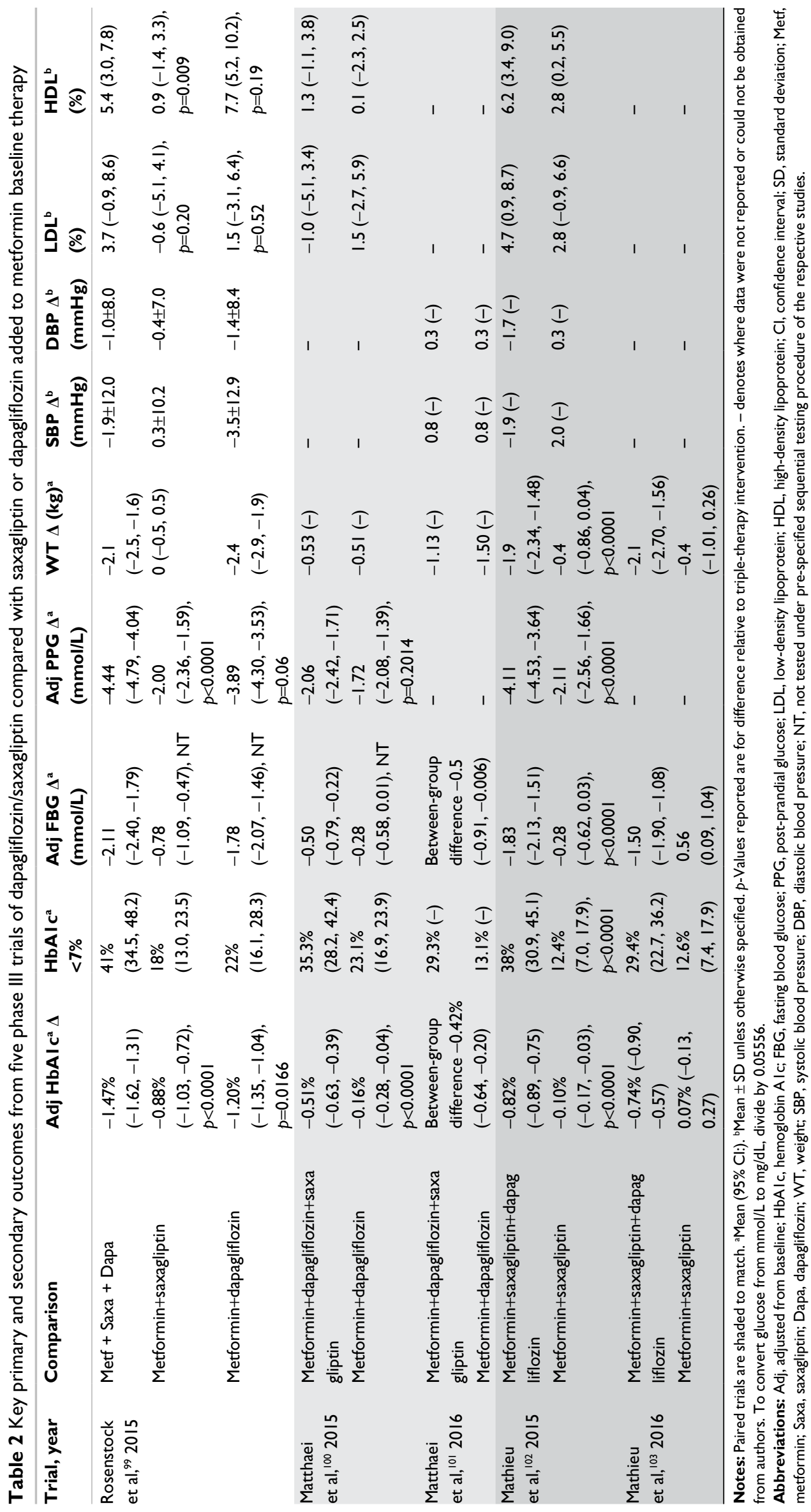




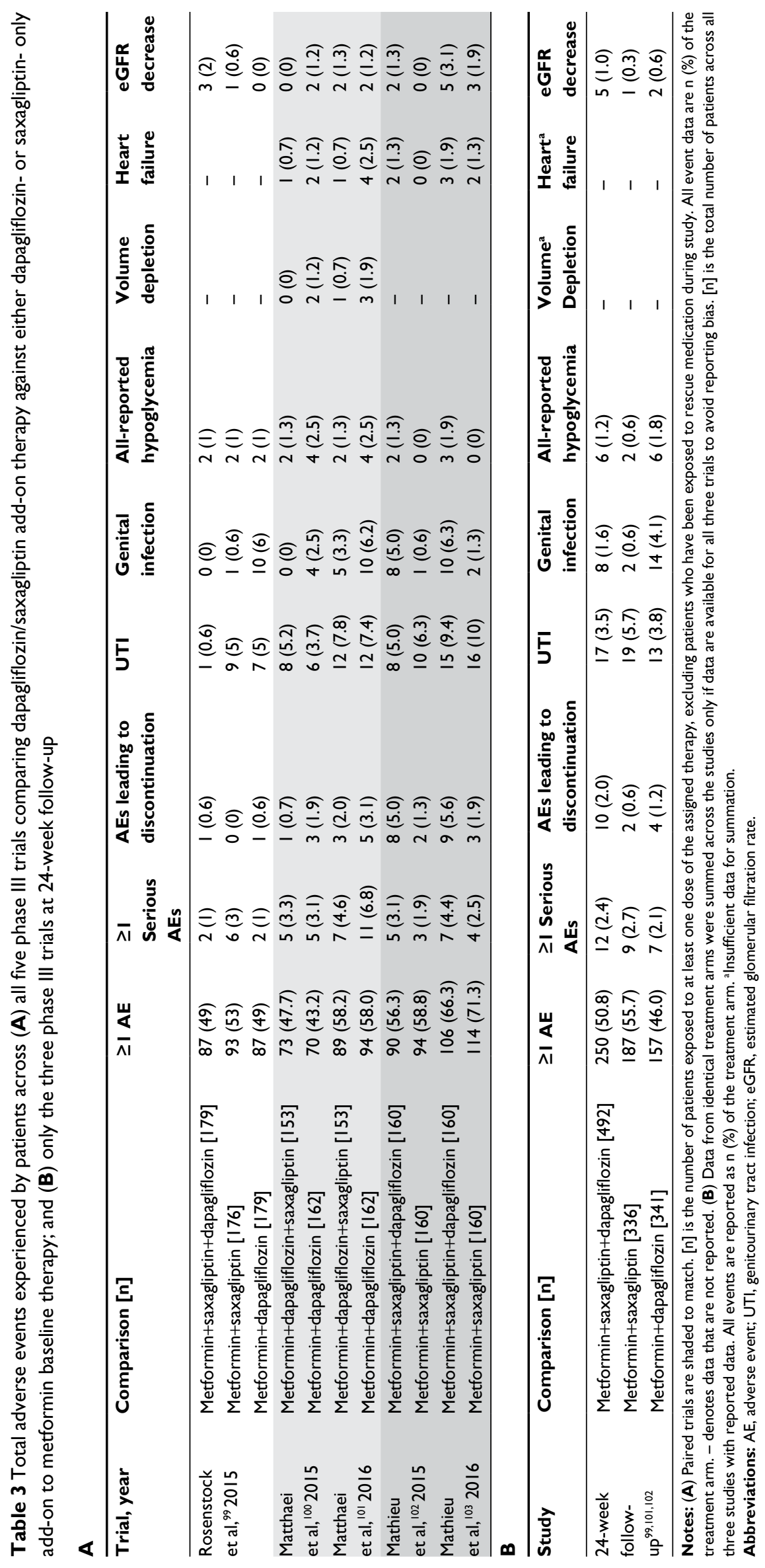


$-1.03,-0.72 ; p<0.0001)$ or dapagliflozin alone $(-1.20 \% ; 95 \%$ CI: $1.35,-1.04 ; p=0.0166) .{ }^{99} \mathrm{~A}$ total of $41 \%$ of the patients on dapagliflozin/saxagliptin achieved target $\mathrm{HbA} 1 \mathrm{c}$ of $<7 \%$, compared with only $18 \%$ of patients on saxagliptin and $22 \%$ of those on dapagliflozin. ${ }^{99} \mathrm{PPG}$ and fasting plasma glucose were also lower than with single add-on therapy. Weight reduction by combined treatment was $-2.1 \mathrm{~kg}(95 \% \mathrm{CI}:-2.5$, -1.6 ), due to the effects of dapagliflozin. ${ }^{99}$

Matthaei et al ${ }^{100}$ examined the effects of dapagliflozin/ saxagliptin added to metformin compared with dapagliflozin alone after 24 weeks with a 52-week extended study. ${ }^{101} \mathrm{In}$ the initial study, 431 patients with $\mathrm{HbA} 1 \mathrm{c}$ between $8.0 \%$ and $11.5 \%$ despite stable-dose metformin completed a 16 -week run-in period with open-label dapagliflozin $10 \mathrm{mg}$ add-on. ${ }^{101}$ A total of 315 (73\%) patients ultimately entered double-blind randomization to saxagliptin $5 \mathrm{mg}$ or placebo; of the 116 patients not randomized, $82 \%$ did not meet inclusion criteria as $\mathrm{HbA} 1 \mathrm{c}$ had improved to $<7 \%$ with dapagliflozin alone. ${ }^{101}$ Glucose-lowering benefits of dapagliflozin/saxagliptin were evident by as early as 6 weeks after randomization and persisted until the end of study. Mean adjusted HbAlc change with dapagliflozin/saxagliptin $(-0.51 \% ; 95 \% \mathrm{CI}:-0.63$, $-0.39)$ was greater than dapagliflozin alone $(-0.16 \% ; 95 \%$ CI: $-0.28,-0.04 ; p<0.0001) .{ }^{101}$ This between-group difference was maintained at 52 weeks $(-0.42 \%$; $95 \%$ CI: -0.64 , $-0.20) .{ }^{101}$ Postprandial glycemic control was assessed using a standardized liquid meal tolerance test, and although the mean adjusted reduction was numerically greater in the dapagliflozin/saxagliptin group at 24 weeks, it was not statistically significant $(p=0.2014) .{ }^{101}$ Weight reduction was similar between the two groups, ${ }^{100,101}$ which is expected given that saxagliptin is weight neutral.

Mathieu et a $\mathrm{l}^{102}$ performed a complementary study examining the efficacy of triple therapy compared with saxagliptin alone in a 24-week study, with follow-up to 52 weeks. ${ }^{103}$ The trial included two strata of patients with poorly controlled DM2: strata A patients were on stable metformin therapy and strata $B$ patients were on stable metformin as well as any maxdose DPP4 inhibitor. Strata A patients underwent a 16-week run-in with added open-label saxagliptin $5 \mathrm{mg}$, whereas strata B patients had their baseline DPP4 inhibitor switched to saxagliptin $5 \mathrm{mg}$ during an 8-week run-in. Ultimately, a total of 320 patients were then randomized to receive dapagliflozin $10 \mathrm{mg}$ or placebo. By 24 weeks, the mean adjusted HbAlc was reduced by $-0.82 \%$ in the dapagliflozin/saxagliptin group (95\% CI: $-0.89,-0.75$ ) compared with only $-0.10 \%$ reduction in the saxagliptin-only group $(95 \% \mathrm{CI}:-0.17,-0.03$; $p<0.0001) ;{ }^{102}$ this was maintained at 52 weeks. ${ }^{103}$ Both FBG and PPG levels were reduced significantly in the combined treatment group at 24 weeks; ${ }^{102}$ this effect was attenuated at 1 year, although combined treatment still maintained a similar reduction in FBG. ${ }^{103}$ Weight was significantly reduced in the saxagliptin/dapagliflozin group by a mean of $-1.9 \mathrm{~kg}$ (95\% CI: $-2.34,-1.48)$ compared with only $-0.4 \mathrm{~kg}(95 \%$ CI: $-0.86,0.04 ; p<0.0001)$ in the saxagliptin-only group ${ }^{102}$ and was maintained at 52-week follow-up. ${ }^{103}$

\section{Tolerability and safety}

Across the five studies, blood pressure was only minimally decreased. ${ }^{99-103}$ The largest reported change was in the 24-week study by Rosenstock et al, ${ }^{99}$ in which the dapagliflozin-only group saw a mean decrease of $-3.5 \mathrm{mmHg}$ in systolic blood pressure, but without events of hypovolemia. In the same study, LDL was also increased minimally from baseline in patients on dapagliflozin, the largest increase being $+3.7 \%$ in the triple-therapy group ( $95 \% \mathrm{CI}:-0.9,8.6),{ }^{99}$ but was statistically nonsignificant compared with the other two treatment arms. These changes are consistent with those seen in other phase III dapagliflozin studies, with no signal toward increased coronary events. ${ }^{83,101}$

Adverse events were low across the studies and similar between treatment arms (Table 3A). When totaled across all three 24-week studies (Table 3B), the proportion of serious adverse events remained low at 2.4\% (12/492 patients) in the triple therapy arms, ${ }^{99,101,102} 2.1 \%(7 / 341)$ in the dapagliflozinonly arm, ${ }^{99,101}$ and $2.7 \%(9 / 336)$ in saxagliptin-only arm..$^{99,102}$ Discontinuation rate for dual add-on therapy was generally low and comparable to single add-on therapy. ${ }^{99,101,102}$ Mathieu et al, ${ }^{102}$ however, found higher rates of discontinuation with triple therapy than with saxagliptin-alone therapy, at 24 weeks ( $5 \%$ vs $1.3 \%)$ and 52 weeks (5.6\% vs $1.9 \%) ;{ }^{103}$ there was no clear trend to account for the increased rate seen in their studies. Hypoglycemia was low across all five phase III trials, ranging from $0 \%$ to $2.5 \% .{ }^{99-103}$ When examining results from all three 24-week follow-up studies, 1.2\% (6/492) of dapagliflozin/saxagliptin patients experienced events consistent with hypoglycemia compared with $1.8 \%(6 / 341)$ of patients in the dapagliflozin-only group and $0.6 \%(2 / 336)$ of patients in the saxagliptin-only group. ${ }^{99,102}$ No events of severe hypoglycemia occurred ${ }^{99,101,102}$ even at 52-week follow-up. ${ }^{100,103}$

UTI rates were comparable between those on dapagliflozin/saxagliptin and those on single-treatment add-on. When the event rates were summed across the 24-week studies, $3.5 \%(17 / 492)^{99,101,102}$ of patients on triple therapy expe- 
rienced a UTI compared with $3.8 \%(19 / 341)^{99,101}$ of patients on dapagliflozin alone and $5.7 \%(19 / 336)$ of patients on saxagliptin alone. ${ }^{99,102}$ Only one patient experienced recurrent vulvovaginal and UTIs requiring medication discontinuation, and this occurred in the dapagliflozin/saxagliptin arm. ${ }^{102}$ There was no report of pyelonephritis in any of the trials. Despite the recognized increased rate of genital infections associated with SGLT2 inhibitor use, ${ }^{68}$ a lower rate was observed across all trials in the combined dapagliflozin/ saxagliptin arm than in the dapagliflozin-only group. ${ }^{99-101}$ At 24 weeks, infection rate was $1.6 \%$ (6/492 patients) in the dapagliflozin/saxagliptin group, $4.1 \%$ (14/341 patients) in dapagliflozin-only group, and $0.6 \%$ (2/336 patients) in saxagliptin-only group..$^{99,102}$ This effect was still observed at 52-week follow-up, ${ }^{100}$ suggestive of a protective effect with combined therapy, although the mechanism is unclear. As in dapagliflozin trials, genital infections were more likely to occur in women. The remainder of adverse events was low and did not increase from individual therapy.

\section{Ongoing trials}

As of February 2017, several studies are ongoing to examine the safety and efficacy of saxagliptin/dapagliflozin combination therapy. One phase III trial to be completed late 2017 will be comparing dual versus single saxagliptin or dapagliflozin add-on to metformin (NCT02681094). An exploratory phase II/III trial is being conducted for dapagliflozin with or without reduced dose of saxagliptin in patients with DM2 and documented chronic kidney disease (NCT02547935). The inclusion criterion includes eGFR $25-75 \mathrm{~mL} / \mathrm{min} / 1.73 \mathrm{~m}^{2}$ with micro- or macroalbuminuria already on an ACEi or ARB.

NCT02419612 and NCT02471404 will further examine the lasting efficacy of dapagliflozin/saxagliptin in extended follow-up, compared with sulfonylurea add-on for glycemic control. Two other trials are examining the role of combination therapy in conjunction with insulin. NCT02551874 will be comparing the adequacy of glycemic control using combined add-on versus basal insulin over 24 weeks in patients on baseline metformin with or without sulfonylurea. A phase IV trial (NCT02965443) will assess if addition of dapagliflozin/ saxagliptin would negate the need for basal-bolus insulin. NCT02946632 is pending recruitment to compare the efficacy and benefit of initial metformin plus dapagliflozin/saxagliptin treatment compared with conventional, stepwise management of drug-naïve DM2 patients. These upcoming studies will better delineate the efficacy and tolerability of combination therapy but more importantly, will establish its role and timing in various diabetes subpopulations.

\section{Discussion}

Owing to progressive $\beta$-cell dysfunction, DM2 patients often require multiple medications to maintain glycemic control over time. ${ }^{6}$ Furthermore, delayed initiation of multiple agents as required increases glucotoxicity and makes glycemic control more difficult. ${ }^{12}$ Many of the add-on agents have undesirable side effects, including weight gain, fluid retention, and/or increased risk of hypoglycemia. Both saxagliptin and dapagliflozin have been shown to produce glycemic benefits and are well tolerated. Importantly, they do not increase the risk of hypoglycemia, even when added to a variety of antihyperglycemic agents. ${ }^{85}$ Saxagliptin is weight neutral, and dapagliflozin can result in weight loss, important considerations given the high prevalence of obesity in this population. ${ }^{9}$ Furthermore, some evidence suggests that dapagliflozin may have renoprotective ${ }^{86}$ and cardiovascular ${ }^{93,94}$ benefits, both common comorbidities in patients with diabetes. Ongoing NCT02547935 trial for combination therapy in chronic kidney disease and NCT01730534 trial for dapagliflozin in cardiovascular outcomes will help clarify these benefits.

Although each medication can be used as individual add-on therapy, dual add-on therapy may be preferred over sequential add-on for those with poor glycemic control, as recommended by major diabetes guidelines. ${ }^{6,12,14}$ Furthermore, these two medications work in complementary mechanisms. Direct comparisons between SGLT2 and DPP4 inhibitors show that after 52 weeks, SGLT2 inhibitors consistently and more potently lower fasting glucose levels. Although both lower PPG, DPP4 inhibitors result in a greater decrement after taking into account their respective fasting glucose-lowering effects $^{29}$ and inhibit the increased glucagon production seen with dapagliflozin. ${ }^{16,17}$ The five completed phase III trials have demonstrated additional glycemic-lowering benefit from combined dapagliflozin/saxagliptin add-on therapy, lowering mean $\mathrm{HbA} 1 \mathrm{c}$ by as much as $-1.47 \%(95 \% \mathrm{CI}:-1.62,-1.31),{ }^{99}$ without significant increase in adverse events even at 52 -week follow-up. ${ }^{100,103}$ Dual add-on therapy resulted in weight loss of $-0.5 \mathrm{~kg}$ to $-2 \mathrm{~kg}$, and may have a protective effect against the genital infections which can occur with dapagliflozin single add-on. For patients with long-standing or severe disease requiring insulin, evidence exists for adding saxagliptin and dapagliflozin, with more patients achieving HbAlc target with less insulin requirement and weight gain. ${ }^{46,84}$ These studies suggest that combined dapagliflozin/saxagliptin add-on to insulin is safe and advantageous.

STC pills have been used in many chronic illnesses such as cardiovascular disease, AIDS, and diabetes. ${ }^{19}$ Not only do they increase compliance, lower cost burden, and improve quality of life, ${ }^{19,21}$ they have been shown to minimize side 
effects while improving glycemic control beyond loosepill combinations. ${ }^{104}$ Other STC therapies in diabetes have been found to be safe and efficacious, including the other SGLT2/DPP4 inhibitor STC empagliflozin/linagliptin. In a review of existing phase III clinical trials using empagliflozin/linagliptin add-on to metformin, it lowered $\mathrm{HbA} 1 \mathrm{c}$ by $-1.19 \% \pm 0.06 \%$ at the maximum dose after 24 weeks, comparable to dapagliflozin/saxagliptin with a similar safety profile. ${ }^{105}$

\section{Conclusion}

The addition of dapagliflozin/saxagliptin takes advantage of complementary mechanisms of action and provides augmented glycemic control. The increased incidence of genital infection seen with dapagliflozin single add-on therapy is attenuated in combined add-on therapy, suggestive of a possible protective effect. It is otherwise well tolerated with a safety profile similar to single add-on therapy, and the risk of hypoglycemia remains low. Therefore, for patients in need of dual add-on therapy or with poorly controlled diabetes despite add-on with either monocomponent, initiation of dapagliflozin/saxagliptin combination is a safe and rational option.

\section{Disclosure}

Dr. Huan Yu has no potential conflicts of interest. Dr. Vincent $\mathrm{C}$ Woo has received funds from the following organizations for speaking, advisory boards, and/or clinical research: Astra Zeneca, Bristol Myers Squibb, Merck, Lilly, Novo Nordisk, Sanofi, Roche, Abbott, Boehringer Ingelheim, Pfizer, Janssen, and Novartis.

\section{References}

1. Cahn A, Cefalu WT. Clinical considerations for use of initial combination therapy in type 2 diabetes. Diabetes Care. 2016;39(suppl 2): S137-S145.

2. Hayward RA, Reaven PD, Wiitala WL, et al. Follow-up of glycemic control and cardiovascular outcomes in type 2 diabetes. NEngl J Med. 2015;372(23):2197-2206.

3. Gerstein HC, Miller ME, Ismail-Beigi F, et al; ACCORD Study Group. Effects of intensive glycaemic control on ischaemic heart disease: analysis of data from the randomised, controlled ACCORD trial. Lancet. 2014;384(9958):1936-1941.

4. ADVANCE Collaborative Group, Patel A, MacMahon S, Chalmers J. Intensive blood glucose control and vascular outcomes in patients with type 2 diabetes. $N$ Engl J Med. 2008;2008(358):2560-2572.

5. Ismail-Beigi F, Craven T, Banerji MA, et al; ACCORD Trial Group. Effect of intensive treatment of hyperglycaemia on microvascular outcomes in type 2 diabetes: an analysis of the ACCORD randomised trial. Lancet. 2010;376(9739):419-430.

6. Inzucchi S, Bergenstal R, Buse JB, et al. Management of hyperglycemia in type 2 diabetes: a patient-centered approach - position statement of the American Diabetes Association (ADA) and the European Association for the Study of Diabetes (EASD). Diabetes Care. 2012;35:1364-1379; 2013;36(2):490.
7. Inkster B, Zammitt NN, Frier BM. Drug-induced hypoglycaemia in type 2 diabetes. Expert Opin Drug Saf. 2012;11(4):597-614.

8. Nesto RW, Bell D, Bonow RO, et al. Thiazolidinedione use, fluid retention, and congestive heart failure: a consensus statement from the American Heart Association and American Diabetes Association. Diabetes Care. 2004;27(1):256-263.

9. Goring S, Hawkins N, Wygant G, et al. Dapagliflozin compared with other oral anti-diabetes treatments when added to metformin monotherapy: a systematic review and network meta-analysis. Diabetes Obes Metab. 2014;16(5):433-442.

10. Florez H, Luo J, Castillo-Florez S, et al. Impact of metformin-induced gastrointestinal symptoms on quality of life and adherence in patients with type 2 diabetes. Postgrad Med. 2010;122(2):112-120.

11. Action to Control Cardiovascular Risk in Diabetes Study Group, Gerstein HC, Miller ME, et al. Effects of intensive glucose lowering in type 2 diabetes. N Engl J Med. 2008;358(24):2545-2559.

12. Canadian Diabetes Association Clinical Practice Guidelines Expert Committee. Canadian Diabetes Association 2013 clinical practice guidelines for the prevention and management of diabetes in Canada. Can J Diabetes. 2013;37(suppl 1):S1-S212.

13. Inzucchi SE, Bergenstal RM, Buse JB, et al. Management of hyperglycemia in type 2 diabetes, 2015: a patient-centered approach - update to a position statement of the American Diabetes Association and the European Association for the Study of Diabetes. Diabetes Care. 2015;38(1):140-149.

14. Garber AJ, Abrahamson MJ, Barzilay JI, et al. AACE/ACE Comprehensive Diabetes Management Algorithm 2015. Endocr Prac. 2015; 21(4):438-447.

15. List JF, Woo V, Morales E, Tang W, Fiedorek FT. Sodium-glucose cotransport inhibition with dapagliflozin in type 2 diabetes. Diabetes Care. 2009;32(4):650-657.

16. Merovci A, Solis-Herrera C, Daniele G, et al. Dapagliflozin improves muscle insulin sensitivity but enhances endogenous glucose production. J Clin Invest. 2014;124(2):509-514.

17. Abdul-Ghani M. Where does combination therapy with an SGLT2 inhibitor plus a DPP-4 inhibitor fit in the management of type 2 diabetes? Diabetes Care. 2015;38(3):373-375.

18. European Medicines Agency. Qtern: EPAR product information. 2016.

19. Thom S, Poulter N, Field J, et al; UMPIRE Collaborative Group. Effects of a fixed-dose combination strategy on adherence and risk factors in patients with or at high risk of CVD: The UMPIRE randomized clinical trial. JAMA. 2013;310(9):918-929.

20. Thayer S, Arondekar B, Harley C, Darkow TE. Adherence to a fixeddose combination of rosiglitazone/glimepiride in subjects switching from monotherapy or dual therapy with a thiazolidinedione and/or a sulfonylurea. Ann Pharmacother. 2010;44(5):791-799.

21. Singh-Franco D. Potential for dipeptidyl peptidase-4 inhibitor and sodium glucose cotransporter 2 inhibitor single-pill combinations. Expert Rev Endocrinol Metab. 2015;10(3):305-317.

22. European Medicines Agency. Qtern: Summary of Product Characteristics. Available from: http://www.ema.europa.eu/docs/en_GB/ document_library/EPAR_-_Product_Information/human/004057/ WC500211093.pdf. Accessed January 25, 2017.

23. U.S. Food and Drug Administration, editor. QTERN Full Prescribing Information. Available from: https:/www.accessdata.fda.gov/drugsatfda_docs/label/2017/209091s000lbl.pdf. Accessed March 17, 2017.

24. Thornberry NA, Gallwitz B. Mechanism of action of inhibitors of dipeptidyl-peptidase-4 (DPP-4). Best Pract Res Clin Endocrinol Metab. 2009;23(4):479-486.

25. Verspohl EJ. Novel therapeutics for type 2 diabetes: incretin hormone mimetics (glucagon-like peptide-1 receptor agonists) and dipeptidyl peptidase-4 inhibitors. Pharmacol Ther. 2009;124(1):113-138.

26. Drucker DJ, Nauck MA. The incretin system: glucagon-like peptide-1 receptor agonists and dipeptidyl peptidase-4 inhibitors in type 2 diabetes. Lancet. 2006;368(9548):1696-1705.

27. Ahrén B, Foley JE. Improved glucose regulation in type 2 diabetic patients with DPP-4 inhibitors: focus on alpha and beta cell function and lipid metabolism. Diabetologia. 2016;59(5):907-917. 
28. Ahrén B. Clinical results of treating type 2 diabetic patients with sitagliptin, vildagliptin or saxagliptin-diabetes control and potential adverse events. Best Pract Res Clin Endocrinol Metab. 2009;23(4):487-498.

29. Schernthaner G, Gross JL, Rosenstock J, et al. Canagliflozin compared with sitagliptin for patients with type 2 diabetes who do not have adequate glycemic control with metformin plus sulfonylurea: a 52-week randomized trial. Diabetes Care. 2013;36(9):2508-2515.

30. Boulton DW. Clinical pharmacokinetics and pharmacodynamics of saxagliptin, a dipeptidyl peptidase-4 inhibitor. Clin Pharmacokinet. 2016;56(1):1-14.

31. Rosenstock J, Sankoh S, List J. Glucose-lowering activity of the dipeptidyl peptidase-4 inhibitor saxagliptin in drug-naive patients with type 2 diabetes. Diabetes Obes Metab. 2008;10(5):376-386.

32. Endocrinologic and Metabolic Drugs Advisory Committee. Briefing Material on NDA 22350: Saxagliptin and NDA 200678: Saxagliptin/ Metformin. Food and Drug Administration (FDA); 2015. Available from: https://www.fda.gov/downloads/advisorycommittees/committeesmeetingmaterials/drugs/endocrinologicandmetabolicdrugsadvisorycommittee/ucm442060.pdf. Accessed December 15, 2016.

33. Scheen A. Pharmacokinetics of dipeptidylpeptidase-4 inhibitors. Diabetes Obes Metab. 2010;12(8):648-658.

34. Deacon CF, Holst JJ. Dipeptidyl peptidase-4 inhibitors for the treatment of type 2 diabetes: comparison, efficacy and safety. Expert Opin Pharmacother. 2013;14(15):2047-2058.

35. Frederich R, McNeill R, Berglind N, Fleming D, Chen R. The efficacy and safety of the dipeptidyl peptidase- 4 inhibitor saxagliptin in treatment-naïve patients with type 2 diabetes mellitus: a randomized controlled trial. Diabetol Metab Syndr. 2012;4(1):36-47.

36. Rosenstock J, Aguilar-Salinas C, Klein E, Nepal S, List J, Chen R. Effect of saxagliptin monotherapy in treatment-naive patients with type 2 diabetes. Curr Med Res Opin. 2009;25(10):2401-2411.

37. Jadzinsky M, Pfützner A, Paz-Pacheco E, et al; CV181-039 Investigators. Saxagliptin given in combination with metformin as initial therapy improves glycaemic control in patients with type 2 diabetes compared with either monotherapy: a randomized controlled trial. Diabetes Obes Metab. 2009;11(6):611-622.

38. DeFronzo RA, Hissa MN, Garber AJ, et al; Saxagliptin 014 Study Group. The efficacy and safety of saxagliptin when added to metformin therapy in patients with inadequately controlled type 2 diabetes with metformin alone. Diabetes Care. 2009;32(9):1649-1655.

39. Gu W, Liang L, Wang S, et al; SUNSHINE Study Group. Efficacy and safety of saxagliptin monotherapy or added to metformin in Chinese patients with type 2 diabetes mellitus: results from the 24-week, postmarketing SUNSHINE study. J Diabetes. 2016;8(6):809-815.

40. Hermans MP, Delibasi T, Farmer I, et al. Effects of saxagliptin added to sub-maximal doses of metformin compared with uptitration of metformin in type 2 diabetes: The PROMPT study. Curr Med Res Opin. 2012;28(10):1635-1645.

41. Li C, Liu X, Bai L, et al. Efficacy and safety of vildagliptin, saxagliptin or sitagliptin as add-on therapy in Chinese patients with type 2 diabetes inadequately controlled with dual combination of traditional oral hypoglycemic agents. Diabetol Metab Syndr. 2014;6(1):69.

42. Chacra AR, Tan GH, Ravichandran S, List J, Chen R; CV181040 Investigators. Safety and efficacy of saxagliptin in combination with submaximal sulphonylurea versus up-titrated sulphonylurea over 76 weeks. Diab Vasc Dis Res. 2011;8(2):150-159.

43. Chacra AR, Tan G, Apanovitch A, et al; CV181-040 Investigators. Saxagliptin added to a submaximal dose of sulphonylurea improves glycaemic control compared with uptitration of sulphonylurea in patients with type 2 diabetes: a randomised controlled trial. Int J Clin Pract. 2009;63(9):1395-1406.

44. Hollander P, Li J, Allen E, Chen R. Saxagliptin added to a thiazolidinedione improves glycemic control in patients with type 2 diabetes and inadequate control on thiazolidinedione alone. J Clin Endocrinol Metabol. 2009;94(12):4810-4819.
45. Hollander PL, Li J, Frederich R, Allen E, Chen R; CV181013 Investigators. Safety and efficacy of saxagliptin added to thiazolidinedione over 76 weeks in patients with type 2 diabetes mellitus. Diab Vasc Dis Res. 2011;8(2):125-135.

46. Barnett AH, Charbonnel B, Donovan M, Fleming D, Chen R. Effect of saxagliptin as add-on therapy in patients with poorly controlled type 2 diabetes on insulin alone or insulin combined with metformin. Curr Med Res Opin. 2012;28(4):513-523.

47. Li FF, Jiang LL, Yan RN, et al. Effects of saxagliptin add-on therapy to insulin on blood glycemic fluctuations in patients with type 2 diabetes: a randomized, control, open-labeled trial. Medicine (Baltimore). 2016;95(43):e5229.

48. Defronzo RA. Banting lecture from the triumvirate to the ominous octet: a new paradigm for the treatment of type 2 diabetes mellitus. Diabetes. 2009;58(4):773-795.

49. Göke B, Gallwitz B, Eriksson J, Hellqvist A, Gause-Nilsson I; D1680C00001 Investigators. Saxagliptin is non-inferior to glipizide in patients with type 2 diabetes mellitus inadequately controlled on metformin alone: a 52-week randomised controlled trial. Int J Clin Pract. 2010;64(12):1619-1631.

50. Göke B, Gallwitz B, Eriksson JG, Hellqvist $\AA$, Gause-Nilsson I. Saxagliptin vs. glipizide as add-on therapy in patients with type 2 diabetes mellitus inadequately controlled on metformin alone: longterm (52-week) extension of a 52-week randomised controlled trial. Int J Clin Pract. 2013;67(4):307-316.

51. Hirshberg B, Parker A, Edelberg H, Donovan M, Iqbal N. Safety of saxagliptin: events of special interest in 9156 patients with type 2 diabetes mellitus. Diabetes Metab Res Rev. 2014;30(7):556-569.

52. Neumiller JJ. Efficacy and safety of saxagliptin as add-on therapy in type 2 diabetes. Clin Diabetes. 2014;32(4):170-177.

53. Cernea S, Cahn A, Raz I. Saxagliptin for the treatment of diabetes - a focus on safety. Expert Opin Drug Saf. 2016;15(5):697-707.

54. Scirica BM, Bhatt DL, Braunwald E, et al. Saxagliptin and cardiovascular outcomes in patients with type 2 diabetes mellitus. $N$ Engl $J$ Med. 2013;369(14):1317-1326.

55. Scirica BM, Braunwald E, Raz I, et al; SAVOR-TIMI 53 Steering Committee and Investigators. Heart failure, saxagliptin, and diabetes mellitus: Observations from the SAVOR-TIMI 53 randomized trial. Circulation. 2014;130(18):1579-1588.

56. Monami M, Dicembrini I, Mannucci E. Dipeptidyl peptidase-4 inhibitors and pancreatitis risk: a meta-analysis of randomized clinical trials. Diabetes Obes Metab. 2014;16(1):48-56.

57. Karyekar CS, Ravichandran S, Allen E, Fleming D, Frederich R. Tolerability and efficacy of glycemic control with saxagliptin in older patients (aged $\geq 65$ years) with inadequately controlled type 2 diabetes mellitus. Clin Interv Aging. 2013;8:419-430.

58. Leiter LA, Teoh H, Braunwald E, et al; SAVOR-TIMI 53 Steering Committee and Investigators. Efficacy and safety of saxagliptin in older participants in the SAVOR-TIMI 53 trial. Diabetes Care. 2015;38(6):1145-1153.

59. Meng W, Ellsworth BA, Nirschl AA, et al. Discovery of dapagliflozin: a potent, selective renal sodium-dependent glucose cotransporter 2 (SGLT2) inhibitor for the treatment of type 2 diabetes. J Med Chem. 2008;51(5):1145-1149.

60. Chao EC, Henry RR. SGLT2 inhibition - a novel strategy for diabetes treatment. Nat Rev Drug Discov. 2010;9(7):551-559.

61. Han S, Hagan DL, Taylor JR, et al. Dapagliflozin, a selective SGLT2 inhibitor, improves glucose homeostasis in normal and diabetic rats. Diabetes. 2008;57(6):1723-1729.

62. Rahmoune H, Thompson PW, Ward JM, Smith CD, Hong G, Brown J. Glucose transporters in human renal proximal tubular cells isolated from the urine of patients with non-insulin-dependent diabetes. Diabetes. 2005;54(12):3427-3434.

63. Komoroski B, Vachharajani N, Boulton D, et al. Dapagliflozin, a novel SGLT2 inhibitor, induces dose-dependent glucosuria in healthy subjects. Clin Pharmacol Ther. 2009;85(5):520-526. 
64. Komoroski B, Vachharajani N, Feng Y, Li L, Kornhauser D, Pfister M. Dapagliflozin, a novel, selective SGLT2 inhibitor, improved glycemic control over 2 weeks in patients with type 2 diabetes mellitus. Clin Pharmacol Ther. 2009;85(5):513-519.

65. Ferrannini E, Ramos SJ, Salsali A, Tang W, List JF. Dapagliflozin monotherapy in type 2 diabetic patients with inadequate glycemic control by diet and exercise: a randomized, double-blind, placebocontrolled, phase 3 trial. Diabetes Care. 2010;33(10):2217-2224.

66. Ji L, Ma J, Li H, et al. Dapagliflozin as monotherapy in drug-naive Asian patients with type 2 diabetes mellitus: a randomized, blinded, prospective phase III study. Clin Ther. 2014;36(1):84.e9-100.e9.

67. Kalra S. Sodium glucose co-transporter-2 (SGLT2) inhibitors: a review of their basic and clinical pharmacology. Diabetes Ther. 2014;5(2):355-366.

68. Anderson SL. Dapagliflozin efficacy and safety: a perspective review. Ther Adv Drug Saf. 2014;5(6):242-254.

69. Bailey C, Iqbal N, T'joen C, List J. Dapagliflozin monotherapy in drug-naïve patients with diabetes: a randomized-controlled trial of low-dose range. Diabetes Obes Metab. 2012;14(10):951-959.

70. FDA Drug Label, editor. Farxiga (dapagliflozin); 2014; No. Reference ID: 3606617.

71. Bailey C, Morales Villegas E, Woo V, Tang W, Ptaszynska A, List J. Efficacy and safety of dapagliflozin monotherapy in people with type 2 diabetes: a randomized double-blind placebo-controlled 102-week trial. Diabet Med. 2015;32(4):531-541.

72. Bolinder J, Ljunggren Ö, Johansson L, et al. Dapagliflozin maintains glycaemic control while reducing weight and body fat mass over 2 years in patients with type 2 diabetes mellitus inadequately controlled on metformin. Diabetes Obes Metab. 2014;16(2):159-169.

73. Bolinder J, Ljunggren Ö, Kullberg J, et al. Effects of dapagliflozin on body weight, total fat mass, and regional adipose tissue distribution in patients with type 2 diabetes mellitus with inadequate glycemic control on metformin. J Clin Endocrinol Metab. 2011;97(3):1020-1031.

74. Strojek K, Yoon K, Hruba V, Sugg J, Langkilde AM, Parikh S. Dapagliflozin added to glimepiride in patients with type 2 diabetes mellitus sustains glycemic control and weight loss over 48 weeks: a randomized, double-blind, parallel-group, placebo-controlled trial. Diabetes Ther. 2014;5(1):267-283.

75. Strojek K, Yoon K, Hruba V, Elze M, Langkilde A, Parikh S. Effect of dapagliflozin in patients with type 2 diabetes who have inadequate glycaemic control with glimepiride: a randomized, 24-week, double-blind, placebo-controlled trial. Diabetes Obes Metab. 2011;13(10):928-938.

76. Bailey CJ, Gross JL, Pieters A, Bastien A, List JF. Effect of dapagliflozin in patients with type 2 diabetes who have inadequate glycaemic control with metformin: a randomised, double-blind, placebo-controlled trial. Lancet. 2010;375(9733):2223-2233.

77. Del Prato S, Nauck M, Durán-Garcia S, et al. Long-term glycaemic response and tolerability of dapagliflozin versus a sulphonylurea as add-on therapy to metformin in patients with type 2 diabetes: 4-year data. Diabetes Obes Metab. 2015;17(6):581-590.

78. Nauck M, Del Prato S, Durán-García S, et al. Durability of glycaemic efficacy over 2 years with dapagliflozin versus glipizide as add-on therapies in patients whose type 2 diabetes mellitus is inadequately controlled with metformin. Diabetes Obes Metab. 2014;16(11):1111-1120.

79. Rosenstock J, Vico M, Wei L, Salsali A, List JF. Effects of dapagliflozin, an SGLT2 inhibitor, on $\mathrm{HbA}(1 \mathrm{c})$, body weight, and hypoglycemia risk in patients with type 2 diabetes inadequately controlled on pioglitazone monotherapy. Diabetes Care. 2012;35(7):1473-1478.

80. Jabbour SA, Hardy E, Sugg J, Parikh S; Study 10 Group. Dapagliflozin is effective as add-on therapy to sitagliptin with or without metformin: a 24-week, multicenter, randomized, double-blind, placebo-controlled study. Diabetes Care. 2014;37(3):740-750.

81. Kaku K, Maegawa H, Tanizawa Y, et al. Dapagliflozin as monotherapy or combination therapy in Japanese patients with type 2 diabetes: an open-label study. Diabetes Ther. 2014;5(2):415-433.

82. Wilding JP, Woo V, Soler NG, et al; Dapagliflozin 006 Study Group. Long-term efficacy of dapagliflozin in patients with type 2 diabetes mellitus receiving high doses of insulin: a randomized trial. Ann Intern Med. 2012;156(6):405-415.
83. Wilding JP, Norwood P, T'joen C, Bastien A, List JF, Fiedorek FT. A study of dapagliflozin in patients with type 2 diabetes receiving high doses of insulin plus insulin sensitizers: applicability of a novel insulin-independent treatment. Diabetes Care. 2009;32(9):1656-1662.

84. Wilding J, Woo V, Rohwedder K, Sugg J, Parikh S; Dapagliflozin 006 Study Group. Dapagliflozin in patients with type 2 diabetes receiving high doses of insulin: efficacy and safety over 2 years. Diabetes Obes Metab. 2014;16(2):124-136.

85. Ptaszynska A, Johnsson KM, Parikh SJ, De Bruin TW, Apanovitch AM, List JF. Safety profile of dapagliflozin for type 2 diabetes: pooled analysis of clinical studies for overall safety and rare events. Drug Safety. 2014;37(10):815-829.

86. Heerspink H, Johnsson E, Gause-Nilsson I, Cain V, Sjöström C. Dapagliflozin reduces albuminuria in patients with diabetes and hypertension receiving rennin-angiotensin blockers. Diabetes Obes Metab. 2016;18(6):590-597.

87. Barnett AH, Mithal A, Manassie J, et al; EMPA-REG RENAL Trial Investigators. Efficacy and safety of empagliflozin added to existing antidiabetes treatment in patients with type 2 diabetes and chronic kidney disease: a randomised, double-blind, placebo-controlled trial. Lancet Diabetes Endocrinol. 2014;2(5):369-384.

88. Johnsson KM, Ptaszynska A, Schmitz B, Sugg J, Parikh SJ, List JF Vulvovaginitis and balanitis in patients with diabetes treated with dapagliflozin. J Diabetes Complications. 2013;27(5):479-484.

89. Johnsson KM, Ptaszynska A, Schmitz B, Sugg J, Parikh SJ, List JF. Urinary tract infections in patients with diabetes treated with dapagliflozin. J Diabetes Complications. 2013;27(5):473-478.

90. Briand F, Mayoux E, Brousseau E, et al. Empagliflozin, via switching metabolism toward lipid utilization, moderately increases LDL cholesterol levels through reduced LDL catabolism. Diabetes. 2016;65(7):2032-2038.

91. Ferrannini E, Muscelli E, Frascerra S, et al. Metabolic response to sodium-glucose cotransporter 2 inhibition in type 2 diabetic patients. J Clin Invest. 2014;124(2):499-508.

92. Daniele G, Xiong J, Solis-Herrera C, et al. Dapagliflozin enhances fat oxidation and ketone production in patients with type 2 diabetes. Diabetes Care. 2016;39(11):2036-2041.

93. Sonesson C, Johansson PA, Johnsson E, Gause-Nilsson I. Cardiovascular effects of dapagliflozin in patients with type 2 diabetes and different risk categories: a meta-analysis. Cardiovasc Diabetol. 2016; 15(1):37.

94. Wu JH, Foote C, Blomster J, et al. Effects of sodium-glucose cotransporter-2 inhibitors on cardiovascular events, death, and major safety outcomes in adults with type 2 diabetes: a systematic review and meta-analysis. Lancet Diabetes Endocrinol. 2016;4(5):411-419.

95. Sattar N, McLaren J, Kristensen SL, Preiss D, McMurray JJ. SGLT2 inhibition and cardiovascular events: why did EMPA-REG outcomes surprise and what were the likely mechanisms? Diabetologia. 2016;59(7): 1333-1339.

96. Hayashi T, Fukui T, Nakanishi N, et al. Dapagliflozin decreases small dense low-density lipoprotein-cholesterol and increases high-density lipoprotein 2-cholesterol in patients with type 2 diabetes: comparison with sitagliptin. Cardiovasc Diabetol. 2017;16(1):8.

97. U.S. Food and Drug Administration [webpage on the Internet]. FDA drug safety communication: FDA revises labels of SGLT2 inhibitors for diabetes to include warnings about too much acid in the blood and serious urinary tract infections; 2016 [updated 2016]. Drug Safety Communications Web site. Available from: http://www.fda.gov/Drugs/ DrugSafety/ucm475463.htm. Accessed January 27, 2017.

98. Handelsman Y, Henry RR, Bloomgarden ZT, et al. American Association of Clinical Endocrinologists and American College of Endocrinology position statement on the association of SGLT-2 inhibitors and diabetic ketoacidosis. Endocr Prac. 2016;22(6):753-762.

99. Rosenstock J, Hansen L, Zee P, et al. Dual add-on therapy in type 2 diabetes poorly controlled with metformin monotherapy: a randomized double-blind trial of saxagliptin plus dapagliflozin addition versus single addition of saxagliptin or dapagliflozin to metformin. Diabetes Care. 2015;38(3):376. 
100. Matthaei S, Catrinoiu D, Celinski A, et al. Randomized, double-blind trial of triple therapy with saxagliptin add-on to dapagliflozin plus metformin in patients with type 2 diabetes. Diabetes Care. 2015;38(11):2018-2024.

101. Matthaei S, Aggarwal N, Garcia-Hernandez P, et al. One-year efficacy and safety of saxagliptin add-on in patients receiving dapagliflozin and metformin. Diabetes Obes Metab. 2016;18(11):1128-1133.

102. Mathieu C, Ranetti AE, Li D, et al. Randomized, double-blind, phase 3 trial of triple therapy with dapagliflozin add-on to saxagliptin plus metformin in type 2 diabetes. Diabetes Care. 2015;38(11):2009-2017.
103. Mathieu C, Herrera Marmolejo M, González González J, et al. Efficacy and safety of triple therapy with dapagliflozin add-on to saxagliptin plus metformin over 52 weeks in patients with type 2 diabetes. Diabetes Obes Metab. 2016;18(11):1134-1137.

104. Bell D. Combine and conquer: advantages and disadvantages of fixed-dose combination therapy. Diabetes Obes Metab. 2013;15(4): 291-300.

105. Woo V. Empagliflozin/linagliptin single-tablet combination: first-inclass treatment option. Int J Clin Pract. 2015;69(12):1427-1437.
Diabetes, Metabolic Syndrome and Obesity: Targets and Therapy is an international, peer-reviewed open-access journal committed to the rapid publication of the latest laboratory and clinical findings in the fields of diabetes, metabolic syndrome and obesity research. Original research, review, case reports, hypothesis formation, expert opinion and commentaries are all considered for publication. The manuscript management system is completely online and includes a very quick and fair peer-review system, which is all easy to use. Visit http://www.dovepress.com/testimonials.php to read real quotes from published authors.

Submit your manuscript here: https://www.dovepress.com/diabetes-metabolic-syndrome-and-obesity-targets-and-therapy-journal 